\title{
Adjectival nodes in structural linguistics
}

\author{
Narmin Aliyeva
}

\section{DOI: 10.18355/XL.2017.10.03.30}

\begin{abstract}
It is known that structural linguistics in Azerbaijan have not been developed, but recently there has been a revival in this area. The article is devoted to the structural syntax. The idea came about nodes in the structural syntax. The hierarchy of verb nodes are in the top of a tree. Studies in this area have been carried out mainly at the verb. Compared to verb nodes, adjectival and adverbial knots are less studied. For this reason, the article examines the issues related to adjectival nodes. Different models of adjectival site analyzed, given the schema.
\end{abstract}

Key words: syntax connection, structural syntax, leading role, member, center offers

\section{Introduction}

Evaluation involves the comparison and has heuristic value. According to Biçici, Way (2016), the establishment of identities and differences is not only the comparison function, as it is characteristic of the process of reflection at all. The definition of comparison as a method of cognition was the basis of inclusion in the structure of the self-assessment element of the conclusion from the comparison. In addition to the designated relations of similarities and differences, the output from the comparison gives an idea of the magnitude or intensity of a particular property in its relation to another.

The views of the majority of scholars agree that the linguistic evaluation value is a structure whose main elements, in turn, do not correspond to components of the logical structure of the evaluation. Lo, Sudjatmika (2016) rightly believes that assessment, included in the context is structurally organized modal framework, which is superimposed on the utterance and does not coincide with its semantic structure, no syntax.

In addition to the main components to the evaluation component will also include the aspect of grading classifiers, motivations, and various means of intensification and deintensification (Gasparyan, 2016), assessment tools (Venturelli, Cabrini, Fruggeri, Cigala, 2016).

There is an opinion that any object of evaluation one way or another is related to the person. So, Rueger (2016) believes that the assessment is most often person directly or through their signs or actions, and often one or another evaluative word or phrase, not even related to any person in an indirect way still characterizes a person. This idea is developed in the study of Tuna, Akbas, Aksoy, Canbaz, Karabiyik, Gonen, Aygun (2016). In their opinion, there are two varieties non values of assessment. The first group includes processes (States, properties, events), i.e. everything that constitutes the environment of human interaction with the world, his immersion into the world. The second type are the facts (the propositions) resulting from the immersion of the world in human consciousness (Araújo, Banisch, 2016).

Analyzing the surrounding reality, a person expresses the attitude towards things, people, phenomena, evaluating them. In the language of assessment is expressed by various means, and is implemented in the component of word meaning, called the evaluation. Studies categories of evaluation still have no clear answer about blown component of evaluation to the structure of the denotative or connotative meaning of the word. Evaluation of seven are being considered as an additional meaning of the 
word "new movement", which is superimposed on the basic denotative meaning of the word; either as part of the denotative aspect of meaning of the word in the form of units, the components of conceptual-evaluative significance. By remark Keine, Bhatt (2016), it is not always possible to decide where ends and begins denotative and connotative, moreover, most speculative connotation is separated from this value; in fact, they can be merged (Abdallah, Gold, Marsden, 2016.).

The key is the difference of views on the essence of connotation, its place in the structure of lexical meaning of the word. Some researchers believe the connotation of part of the lexical meaning. For example, Maruyama (2016) calls the connotation aspect of the lexical meaning of the units by which kodification to Express the emotional state of the speaker and due to this condition the relation to the recipient, the subject and the object of speech, as well as the situation in which the activity is communication (Beckage, Colunga, 2016). Onishi (2016) considers the connotation as a special macro component of word meaning, determining the ability of lexical items to signal about the value attitude of a subject towards the world. Grama, Kerkhoff, Wijnen (2016) define connotation in linguistics as peripheral components of the semantics of words.

The sum of a meaningful component values determines the connotation of researchers such as Martins, Martins, Fitch (2016).

At the same time, Biria, Bahadoran-Baghbaderani (2016) believe the connotations are not the semantic component, as part of the pragmatics of the word, reflecting the word associated with the cultural performances and traditions prevailing in the society the practice of using these things and many other non-linguistic factors. The connotations of the lexeme, the researcher suggests to call insignificant, but steady signs Express her concepts, which embody the adopted language in this collective assessment of the relevant object or fact of reality. Don't think the connotation of part of the semantics of words and some other researchers (Lenk, 2016).

In the case of a narrow understanding of the connotative values of some linguists equate it to the stylistic value of using these terms as synonyms, or consider it as contextual and stylistic value, which contrasted with absolute stylistic value.

Sometimes the connotation is equivalent to the emotional value, when the whole vocabulary, stylistically non-neutral, it is considered emotional. And that part of the value that carries information about emotion, is called connotation.

Of the interconnection and interdependence of the category of modality and its connotations, says Crossley, Kyle, McNamara (2016). They believe that all language entities, which have the connotation, give the text subjective modality.

The opposite view is held by scientists who consider modality and evaluation as different linguistic phenomena. So, Francez (2016) considers assessment as a category comprising modality. According to the researcher, the estimates can be considered a wide range of subjective, emotional, modal, rational, alethic, persuasive, temporal, spatial, existential relations.

Proponents of a broad understanding of the connotation I believe that some researchers, viewing it as part of a language system, limited only stylistic framework, diminish the important role of connotation in lexical meaning of the word. D Asaro, Di Gangi, Perticone, Tabacchi (2016) noted that the connotation of necessarily interconnected with the human experience, resulting from his upbringing within a particular culture.

Such an understanding of connotative values distinguishes the work Gasimov (2015), who considered connotative of any secondary information. Weideman (2017) connects connotation with the conditions and participants of communication, considering the connotation part of speech information.

Biria, Bahadoran-Baghbaderani (2016) exclude the stylistic component from the connotation, equated to the author's works to the concept of "expressiveness", 
considering the main elements of its structure, evaluation and emotion. These elements in the studies combined the concept of "emotional evaluation" as are the linguistic level, components of word meaning. In addition to the mandatory components, the authors highlight the intensity and shape as the periphery of the connotative content.

\section{Methodology and text analysis}

Analyzing connotative signs in their entirety, Yalçin-Heckmann, Aivazishvili (2012) distinguish the semantic structure of the word "meaning" and "halftone", the combined term "connotation". In his study, the author follows the four-part structure connotative values, main components of which are: evaluation as positive or negative characteristics of the object laid down in the word; the imagery as reflective category. expression (expression, expression) as a connotative sign, which is based on deliberately laid a mismatch of language or speech means language norms; emotion as a psychological category, which in the language expressed in the interjections, affixal formations and intonation of speech (Björklund, Fernau, 2016).

Note that the word can be combined completely different number of "meanings". So, In Yalçin-Heckmann, Aivazishvili (2012) proposed to represent the connotative signs in the form of four overlapping circles (evaluation, emotionality, expressiveness and imagery), the total area of which will represent the word that combines all the elements connotation. A similar circuit is shown, but marked with three circles in accordance with the number of allocated elements: imagery, according to the author, is not a separate component of the connotative value.

In the works of some scientists of the category of emotion and evaluation are merged into one component connotations. For example, Ferreira (2016). notes: evaluation, presented as the correlation of words and emotion that is associated with emotions, feelings, do not constitute two different components values, they are unanimous. Assessment, according to the researcher, not just accompanied by the appropriate emotion, but as it absorbs it in itself, the parameters of evaluation and emotions are the same: "nice" - "good", "bad" - "bad". Category that combines both concepts, called "emotional evaluation". A similar view is shared by Tuna, Akbas, Aksoy, Canbaz, Karabiyik, Gonen, Aygun (2016). According to them, in a direct communicative act estimation cannot be accompanied by emotions.

The choice of sign of emotional evaluation (positive or negative) less reasoned and motivated, compared to rational evaluation. Due to the fact that the motive of the evaluation is often not verbalized, to determine the basis of emotional evaluation becomes extremely difficult. So, the motives of some types of emotional evaluation of difficult explication (Giuffrè, 2017).

Based on the separation of rational and emotional evaluations, and recognizing the interrelatedness of evaluation and emotive, Evaluative the word is not always emotive, while the emotive component of meaning is always evaluative: in cases of rational assessment of the meaning of the word emotive is characterized by a zero component. In addition, recognizing the possibility of integration of emotive and evaluative components in the meaning of the word, the researcher recognizes the leading role of emotive in this process.

In language, there are inherently adherently and emotional evaluation. Under inherently emotional assessment, the author understands the emotional response and evaluate the speaking of some object that reflected the consciousness and embodied in the meaning of the lexeme as an independent invariant SEMA. In a speech this emotional evaluation is realized in specific forms (clumsy, piss artist, a treasure). In contrast, adherentsa emotional assessment is not fixed in meaning, but actualization this word only in a certain context. 


\section{A combination of a local Azerbaijani adverbial sentences}

In traditional grammar the sentence is represented thus: subject and predicate they are the main members of the sentence, wherein the subject has a leading role; all other members of the proposal, including the predicate under his control; definition, addition and circumstances are secondary members of the sentence. Only the Azerbaijani linguist find a different approach to the question of sentence. He believes that the main part of the sentence is the predicate, the subject and object is the primary sentence, definition and the fact that members of the secondary supply. Conjunctions, postpositions, particles, interjections, etc. are accepted by the people. But neither the first nor the second view of the sentence is not acceptable for the syntax of structural grammar.

It is not that they do not reflect objective reality. The fact that they do not give an objective view about the hierarchical dependencies of words in a sentence. That is why in structural linguistics arose the idea of the communication nodes. A node is a combination of words with one driving element (word) that controls all other elements (words). Every meaningful word is able to form a knot. We will distinguish as many node types as there are types of meaningful words, namely four: verbal node, the node noun, adjectival and adverbial node. Adjectival node is the node whose center is an adjective. In the structural syntax of the sentence is also classified in accordance with the nature of the Central nodes: (1) verbal sentence, (2) substantive proposal, (3) adjectival sentence and (4) the adverbial sentence.

We first consider the adjectival node, and then the associated adjectival sentence.

The greater the valence of the words, the greater the compatibility. The valence, i.e. the compatibility of the verb more than substantive, so the number of possible types of sub-elements of the verb more than substantive, in turn, the valence, i.e. the compatibility substantive has more than an adjective, so the number of possible types of child elements from a noun more than an adjective. This formula is expressed as: as we descend lower on a hierarchy of nodes, the number of possible types of child elements is gradually reduced. In particular, the adjective can have as a sub element is only an adverb. Possible ways to deploy the site with the centre of the adjective (or adjectival node), thus greatly narrowed (Iosad, 2016).

All the world's languages as a sub-element of the adjective acts as an adverb. This quality is even reflected in the definition of adverb: a part of speech that determines the movement or status and is called an adverb. An adverb, which determines the movement or status of (i.e. the verb) is included in the verb node. As an adverb defining the quality (i.e. the adjective) is part of the adjectival host. The adverb in the function of a dependent of a member of this node in the schema is submitted under the adjective and the adjective is connected with a vertical line the syntactic relationship:

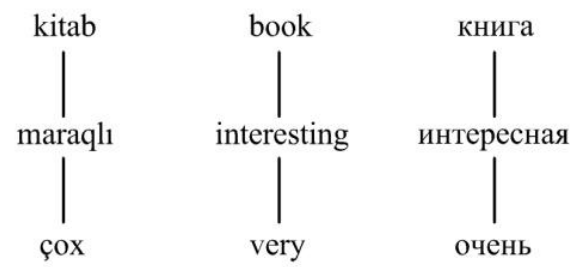

Figure 1. The combination of the sentence in the structural syntax of the line. 
Usually in most of the world's languages in written or oral speech chain the adverb precedes the adjective, i.e. is prepositioned position - the first is an adverb, and then the adjective: Azerbaijani. çox (olduqca) gözəl, eng. very good, it. sehr gut, Talysh. ve çok. The Talysh language belongs to the Iranian group of the IndoEuropean family of languages, it is an adverb with a preposition in relation to the adjective. And incoming with him in the same group in the Persian language in relation to the adjective, the adverb is postpositional position: ğəşənğe be siyar "very beautiful". Persian is not the only language with a similar structure; in other languages (with the exception of the Talysh language) of that group there is a similar location. In addition to the Iranian group of languages in some languages, has a strong centrifugal order of the elements, the adverb sometimes follows the adjective, as in the Persian language.

The adjective has the ability to subdue the adverb - circumstant. This ability, i.e. to have as a sub-element dialect - circumstant, it is, in some measure, moving closer to the verb. So it can perform the function of predicate. In this function, the adjective is reflected in the definition of a predicative adjective. The fact that in some IndoEuropean languages, for example, in the Russian language, adjectives are used in two versions: full and truncated versions. In Russian linguistic literature they are called full and short adjectives. Short adjectives in combination with auxiliary verbs often perform the function of the predicate of the sentence, i.e. the predicate. For example: Soon he was ready to join the fight for the throne (Khan, Lee, Park, Park, 2016). Therefore, in the Western linguistic literature are often called short adjectives predicative adjectives. But, it should be noted that the verb can manage and actants, and circonstance, and the adjective to control the actants can't; it governs only circostante. This, from a structural point of view, is the profound difference that exists between verb and adjective.

In the French language of the signs that difference can be traced to dialects, however, relatively rare. Thus, the two adverbs of the same value and "very" are mostly used: the first with adjectives, the second with the verb: "very beautiful book", "This book is very beautiful", "This book I really like."

With regard to the compatibility of some adverbs in some an adjective or a verb, this is not a feature of French or another language; in all languages there are words, including adverbs which word (whether an adjective or a verb) can be combined: one with the adjective, the other with verb. For example, adverbs and çox olduqca in the Azerbaijani language have the same meaning - so, but combined both with an adjective and an adverb with the verb do not match: çox gözəl "very beautiful" and olduqca gözəl "very beautiful" is used, çox gəlir "often comes" is used in a dialect "olduqca" combined with the adjective, with no verb. The combinability of some words by other words or irreconcilability of some words with others is a national feature of languages is the semantic universalism.

These author further reading: further Analyzing the difference between a verb and an adjective, we find that the verb is primarily a means of expression of a process, action or condition. And precisely because it expresses the processes of action, he should be able to manage the actants. But if it's a verb or predicative adjective condition, then it requires only circonstances.

Depending on the nature of circonstances there is still one difference. Regardless of the nature of all circumstance can determine the process. As for the spatial circonstances, that is circonstance of time and place, they are almost required for the characterisation of time and space, conditions of implementation process - the action or state expressed by the verb or predicative adjective, and instead, they fail to find a circumstance in attribute definitions, in which the notion of process is absent. 
Therefore, the adjective - attributive definition may have as dependent members only adverbs of manner and quantity (Nefdt, 2016).

It seems to detect that the verb "is primarily a means of expression of a process, action or state" no tests are necessary; they are qualities of a verb are included in the definition (Xia, Lewis, Goodman, Slayden, Georgi, Crowgey, Bender, 2016.). The verb as part of speech, and classical linguistics manages the other members suggestions, even though we usually close our eyes to it, subject of the sentence. As we have pointed out, the only main part of the sentence considers the verb (or rather predicate). Time management is the other words of the sentence included in the nature of a verb, of course, in structural linguistics, the verb has the ability to control the actants, which includes not only addition, but even the subject of classical syntax. But not all verbs require the office of actants. For example, the verbs state, by its nature, require only circonstances. It should be noted that not only state verbs, but also predicative adjectives, i.e. adjectives short when they assume the role of the predicate in the structural syntax, require circonstances.

That peculiar adjective characteristic of those words, which under certain conditions can replace the adjective. Such words, for example, are nouns and adverbs (in the structural syntax of the pronoun also takes the noun).

\section{The development of language in the structure of social development}

This classification of emotion (without considering its relationship to the category of evaluation) seems fair. In words, an emotional content which is the core value in a certain context and with a certain intonation in speech emotion becomes the connotative sign, e.g.: adjective happy, which contains the emotion "joy" in the denotative component values, in the proposal I'm happy for you that involve, for example, losing an athlete of his fortunate rival, with appropriate intonation can Express the emotion of "irritation".

It should be noted that the estimated statement is influenced by several factors: vital position of the subject evaluation, value system, his mental state etc. In this regard, the evaluation of the same event, object, person, data subject in different psychological States, with different moods, may vary. Therefore, in some cases a rational assessment becomes emotional under the influence of a certain psychological state of the subject, for example: rational evaluative adjective clever spoken man, irritated by anything, using appropriate intonation gets emotional in the structure of connotative meanings of the word: Ms. You're the smart one.

Thus, evaluation and emotion are two interrelated and interdependent but different connotative signs. If evaluation is understood as laid down in the word a positive or negative characteristic of an object (person, object, phenomenon), the emotionality is seen as reflected in the semantics of words (or inherent adherent) attitude, a sense of the speaker to the object of speech.

Before we talk about expressivity as a component of the connotative content of the lexical meaning, it is necessary to distinguish between the concepts of expressivity and expression. The authors of "Linguistic encyclopedic dictionary" define expressiveness as a set of semantic-stylistic features of language units, that ensure its ability to act in a communicative act as a means of subjective expression of the relationship of the speaker to the content or the addressee of speech and expression is interpreted as the ability of the expression of the mental state of the speaker acquired by the speech as a result of the actualization of the expressive means of the language, the combination and interaction of which allows almost any language to act as a carrier of expressive. In other words, the expression acts as a linguistic phenomenon, as expression as a result of the updating of the expressivity on the speech level (Yang, Li, Zhu, 2016). 
The definition of language expressiveness as a component of the connotative value is quite controversial. Some consider the expression as an amplification of expression and increase the force of impact on the perception of the listener. Expression is everything that makes the speech more vivid, strongly established, deeply impressive. This view of the problem of the definition of expressiveness is found in the research - discusses the expressiveness as increased quality or quantity of the signal depending on some argument, i.e. the additional information that leads to this increased and causes an increased reaction to the signal. In addition, we believe that the word contains an expressive, if your imagery or some other way stresses, enhances what is called in the same word or in other syntactically related words.

The other notion of expressiveness is considered as one of the types of "emotive values". In the works of some researchers stands out semantic and stylistic expressiveness. So, semantic expressiveness is reduced to a language that has a system of means at different levels of language that are used to actual realization in the speech of the expressive function of language. At the same time, stylistic expressiveness - speech phenomenon, which is generated consciously by the author through a system of expressive language means and stylistic devices.

The view that the basis of the expression lies the inconsistency of language means language standards consonant with the point of view that considers the dependence of expression of words by three main factors: the imagery, the intensity of the characteristic actions and "novelty" of a language unit.

Lexical expressivity is directly linked to components such as imagery, emotion, evaluation and intensity.

Often included in the composition of expressive vocabulary words that represent "emotional evaluation" (splotchy, minx), and exclude units, actualized intellectual assessment (good, good, ripe). The latter have a purely evaluative, without expression, value.

We will illustrate the presence or absence of lexical expressive components of connotation (imagery, evaluation, emotion and intensity), for example, their isolated use, and some combinations within the same word (Table. 1).

We did not determine the actual emotion, because, as has been said, emotion always involves an assessment.

Table 1. Lexical expressive components of connotation

\begin{tabular}{|l|c|c|}
\hline $\begin{array}{c}\text { The connotation component or } \\
\text { combination of components } \\
\text { Evaluation }\end{array}$ & $\begin{array}{c}\text { His decision is } \\
\text { ess }\end{array}$ & - \\
\hline advisable & Scarf brick red & - \\
\hline Tmagery & $\begin{array}{c}\text { The blow was a } \\
\text { huge force }\end{array}$ & - \\
\hline Evaluation + intensity & $\begin{array}{l}\text { He's a very bad } \\
\text { friend }\end{array}$ & - \\
\hline $\begin{array}{c}\text { He's a terrific } \\
\text { conversationalist }\end{array}$ & + \\
\hline Evaluation + emotional & $\begin{array}{l}\text { He's a scary man } \\
\text { Imagery + evaluation }\end{array}$ & + \\
\hline Imagery + emotion + attitude & $\begin{array}{c}\text { His behavior was gold } \\
\text { beastly }\end{array}$ & + \\
\hline The shape + intensity + & This is a very hard & + \\
\hline
\end{tabular}

XLinguae Journal, Volume 10 Issue 3, June 2017, ISSN 1337-8384 


\begin{tabular}{|c|c|c|c|c|}
\hline evaluation & & & man & \\
\hline \multirow[t]{2}{*}{$\begin{array}{l}\text { Emotional } \\
\text { evaluation }\end{array}$} & \multirow[t]{2}{*}{$+\quad$ intensity } & & $\begin{array}{l}\text { This is a very } \\
\text { curious fact }\end{array}$ & + \\
\hline & & & $\begin{array}{l}\text { This delightful } \\
\text { music }\end{array}$ & + \\
\hline
\end{tabular}

Thus, the lexical expression can be called a property of words including connotative components: words containing emotion, always expressive; the intensity combined with the evaluation, depending on the type of intensifier, can endow or not to endow the word expressiveness; and the words comprising the isolated evaluation, imagery or intensity (with no other "halftone" setting), do not possess expressiveness.

In this regard, we think a reasonable definition of expressivity as the properties of speech to increase the impact force of the utterance due to the presence in its semantics of components such as imagery, emotional intensity, etc. Based on this definition reflects the interrelation of the components of the connotative values (imagery, evaluation, emotion, and intensity) in the form of four intersecting circles, the area of intersection of which is the expression.

Such an interpretation of expressiveness found in the study of the expression should be understood as a functional property of a language unit that it is capable of expressive, vividly convey the mental content of the speech, to picture the reality. Depending on the means of expression of the researcher highlights the expressiveness of intensity, expressiveness of emotion, expression evaluation, expressiveness of imagery and expressiveness of associations.

\section{Influence on the dialects of the national language international forms}

Along with General evaluative words, there are words such as pleasant, sad, desirable, harmful, kind, forming a more extensive and diverse group of private sentiment lexicon. In these word meanings assesses one aspect of the object from a certain point of view, that is, the classification of private estimates on the interaction of the subject of evaluation with its object.

Among private estimates there are three groups that include seven digits. The first group of sensory evaluation that are associated with feelings, sensory experience and is divided into:

- $\quad$ sensory-taste, or a hedonistic evaluation, expressing impressions, which arise in the human mind when perceiving something with the senses (pleasant - unpleasant, tasty, tasteless, attractive - unattractive, fragrant foul-smelling; what one likes, dislikes, etc.);

- psychological assessment, comprising, in turn:

a) intellectual assessment: intelligent, fascinating, interesting, deep, exciting - a stupid, unexciting, uninteresting, boring, superficial, trivial;

b) the emotional evaluation: joyful - sad, cheerful - sad, welcome unwelcome, unwanted, pleasant - unpleasant.

The second group is made up of sublimated rating:

- aesthetic assessment based on a synthesis of sensory-taste and psychological assessments, and indicate the emotional and the mental impressions of perception of anything: beautiful - ugly, beautiful, ugly, ugly;

- ethical evaluation, which represent the reaction of our consciousness, based on socially constructed ideas about the moral norms of good and evil: moral - immoral, decent - indecent, moral and immoral, good and evil, virtuous and vicious. 
Sublimated assessment "rise above the sensory evaluations, humaniterra them. Aesthetic evaluation associated with satisfaction sense of beauty, ethical - satisfaction of the moral sense.

The third group - rationalist evaluations related to practical activities, interests and daily experiences of man. Main categories - physical and mental benefits, focus on achieving certain goals, performing certain functions, according to the established standard. Discharges rationalist evaluations:

- utilitarian evaluation: beneficial - harmful favorable unfavorable, convenient - inconvenient, practical - impractical;

- regulatory evaluation: right - wrong, correct - incorrect, normal abnormal, abnormal; standard - non-standard, defective; benign - poor, healthy - sick;

- teleological evaluation: effective, ineffective, appropriate inappropriate, successful - unsuccessful.

Classification, offered by us, includes several aspects and allows to separate the actual estimated values of the characteristics in which evaluation is combined with a descriptive. In addition, this typology allows to determine a degree of emotionality / rationality in the structure of private estimates: for example, sensory-taste and aesthetic evaluation is far more emotional than intellectual.

The classification, proposed by us, was the starting point for creating other types of estimates. In particular, we have combined into a single typology of evaluative predicates based on the notions of modality, correlating it with the classification of estimates according to the principle of the presence or absence of emotive component in the structure of the estimated values. We offer the following types of evaluative predicates:

- modal and evaluative predicates expressing evaluation from the point of view of necessity and obligation: necessary, needed, needs, etc.; evaluative predicates of this type simply reflect a rational assessment;

- general evaluative predicates denote both situational and substantive assessment: good, bad, great, bad, etc.; this type of estimates is rational-emotional in nature;

- $\quad$ private evaluative predicates expressing or rational, or emotional evaluation; the variety includes:

a) utilitarian predicates expressing a rational assessment of someone, something or from the point of view of utility, the possibility of using in various purposes: beneficial, favorable, harmful, disadvantageous, etc.;

b) ethical predicates, denoting the reaction of our consciousness (especially the mind) and based on socially constructed ideas about the moral norms of good and evil: good, humane, evil, cruel, honest, modest, etc.; expresses a rational assessment;

c) aesthetic predicates denoting emotional and mental impressions of perception (mainly visual and auditory) someone, something: beautiful, charming, ugly, unattractive, etc.;

d) the sensory or hedonic, the predicates Express only the impressions that arise in our consciousness when perceiving something with the senses (vision, hearing, smell, touch): pleasant, unpleasant, nasty, delicious, etc.;

- 4) ligamentous or axiological (relative), predicates represent the method of representation (the process) assessment: mental (count, find, someone, good, beautiful), perceptual (to seem, to look beautiful, be funny), emotional (feel bad, to blame), and behavioral (behave, act well, honestly). 
More fractional classification of assessments provided to us. We offer to provide:

- axiological evaluation (ethical, aesthetic, utilitarian, political, religious, emotional);

- $\quad$ modal assessment (necessity, obligation, possibility);

- existential evaluation;

- $\quad$ timing of assessment;

- $\quad$ the assessment of the values;

- a spatial evaluation.

Thus, the problem of the ambiguity of the interpretation of the language categories of assessment is the main reason for the lack of a uniform classification of estimates - the other, no less important problems of study assessment categories in linguistics. Discussed above typologies are based usually on single eligibility criteria (based on the axiological interpretation of the method of estimation, the presence or absence of emotive component, etc.) that allows you to analyze the evaluation unit in the corresponding dimension. However, a comprehensive analysis of assessment tools the choice of any one classification is insufficient. As a result, there is a need to create a single multidimensional typology, reflecting the complexity of the evaluation values. One of the main objectives of the present study is the analysis of the implementation of the above types of estimates.

Adjectives represent a special part of speech for the expression evaluation function in the language. The specificity of their linguistic nature is in the position they occupy among other parts of speech.

Adjectives are one type of indicative words, defined as a syntactically specialized in indicative function meaningful words with a lexical meaning of the sign. To the indicative words along with adjectives include verbs and adverbs. The words of all these parts of speech reflect the diversity of the relations of objects and their characteristics, and their assessment of the subject knows the world. However, unlike adverbs, which Express the symptom of symptom, verbs, manifested procedural features (actions, States), the semantics of adjectives refers to non-procedural characteristics (quality, relations, properties). The notion about the name of adjective as a class of words which refers to the passive features of the subject, reflected in the works.

The connection of the adjective with the noun is implemented either in the attributive construction when the adjective acts as the definition of a noun, either as the predicate or its part, being United with the noun by means of a copular verb. Such attributive predicative nature of the adjective is its main functional feature, as expressed in its definition. An adjective is a part of speech characterized by the categorical value of the attribute, the grammatical category of degrees of comparison gender, number, case, expressed in the form of coordination, the syntactic use in the function definition (a function attribute) and predicative member and a developed system of word-formation models.

In addition, attributive and predicative functions of the communicative potential of an adjective in the text. The execution attribute of the function inherent in both qualitative and relative adjectives, since it is a categorical grammatical symptom of an adjective as parts of speech, while the predicative syntactic function is carried out among the adjectives mainly to the category of qualitative adjectives, approaching this with verbs.

Being a classic or "pure" predicates, qualitative adjectives reflect our view of the world, being focused on the knowing subject. Despite the fact that words of a given lexical-grammatical category of able to perform attributive and predicative function, even a typical attribute combination with qualitative adjectives prototypically associated with the predicate. Speaking as the definition of a noun, quality adjectives 
are a kind of linguistic stereotypes for the implementation of previously made, but irrelevant to the moment of the speech act of predication. So, for example, the definition of man noun by the adjective clever associative refers to a situation when the object of evaluation showed themselves accordingly: a smart man is a smart man.

If we consider the quality value of the subject as prototypical for the name of the adjective, note that qualitative adjectives have the lexical and grammatical properties of this part of speech to the greatest extent.

Being a complete dictionary words, adjectives answer it probabilistic, discretecontinuous nature, does not allow a strict distinction in explanation of such types of cognitive structures as knowledge, opinion, evaluation. This is because standing behind the word concept used in cognitive, emotional, volitional spheres, which represent the indivisible unity of human subjectivity, is not limited. Conceptual space is the system of opinions and knowledge about the world, reflecting his learning experience on coaticook and linguistic levels.

The main tool for expressing an opinion on the subject, the person, evaluation is a lexical semantic category of qualitative adjectives. The knowledge of the subject through his signs clearly speaks in the vocabulary of the interpretation of nouns. Consider the nouns - names of animals - in the figurative sense denoting the people, endowed with certain qualities. Most of them are in the dictionary are characterized by the transfer of agreed qualitative adjectives in combination with nouns with the meaning of person (man, woman, girl, etc.); for example, in BTS, you can find a similar evaluation of the interpretation of the following nouns: Fox $-===$ we speak of the cunning, flattering man', pig $===$ we speak about the dirty, unkempt man with vile habits', goose $-===$ we speak about a person unreliable, roguish, clever', cock $-===$ we speak about cocky, passionate man', the elephant $-===$ we speak about the high, thick, clumsy man', forty $===$ we speak about a talkative, noisy person' crow $-===$ we speak about scattered, inattentive man', the chicken $-==$ we speak about weak-willed, spineless man', goat == = we speak about high-spirited, lively girl'. That is categorical semantics of quality determines the ability of adjectives to define nouns, expressing at the same estimated response.

As classical predicates, qualitative adjectives able to act simultaneously within a single act of communication, in denotative and qualificational structures. This property is due to the fact that the implementation of active, changeable characteristic, expressed an adjective quality, is possible in the case of measuring a given characteristic of the subject that, in turn, unusual for a relative adjective. So, when considering cognitive functions of adjectives, noted significant differences in the semantics of qualitative and relative adjectives. If the semantics of qualitative adjectives paramount opinion of the subject (collective or individual", the relative adjectives Express the "knowledge of the conceptual character of the object of a particular class.

From this it follows that method of characterization in qualitative and relative adjectives, which are describing the verbal signs are different: subjective quality of adjectives, because it involves the participation of the speaker and its evaluation; and objective from a relative, because it reflects knowledge of the speaker about the signs of the subject of this class. Talking about gradations of objectivity and charts among parts of speech, starting with the most substantive nouns the substantives with the gradual increase of charts first in relative adjectives, and then at qualitative adjectives, verbs and adverbs. Such a gradation can be represented in the form of a dial, the extreme points of which will be nouns on the one hand and adverbs on the other. Given the advantage. a river of adjectives in the present study, we consider only that part of the scale that deals specifically with this part of speech. The indicator of 
subjectivity in the relative adjectives is higher than the qualitative, and Vice versa, the rate of charts qualitative adjectives is higher than the relative.

With the development of charts in the meaning of adjectives different discharges associated strengthening their evaluation capacity. Adjectives in its semantics constitute a continuous series from the actual evaluative (good / bad) to adjectives, deprived of estimates (relative adjectives), and the intermediate group consists of adjectives that combine an indication of the sign and the property qualification for quality (SEMA good / bad) or number (Sam a lot / little). In this respect we can speak about the grade of evaluation in the structure of the value of adjectives.

The distribution shown on the scale of semantic groups of adjectives are caused, firstly, by the division of adjectives into qualitative and relative, and second, the conventional division of the category of qualitative adjectives on the estimated and not estimated. Evaluative adjectives, in turn, include an overall evaluation and a private evaluation Evaluative adjectives are not adjectives characterizing the object (phenomenon, entity) according to different parameters (weight, color, size, shape, position in space, etc.). For the scale of the estimated potential it is possible to allocate following groups of adjectives:

Relative adjectives used in a literal value, type, factory, glass, Azerbaijani (OP in a direct sense), in which there is no evaluative component.

Qualitative adjectives non-judgmental in a direct sense, characterizing the subject on the grounds of color, shape and other physical parameters, such as the brown (Desk), cold (metal), high (Cabinet) (KP-parametric unbiased).

Relative adjectives in the literal sense, in which the evaluation component appears only in a certain context, based on the value of the scale adopted between the addressee and the addresser (OP contextual evaluation). For example, in the dialogue: - He gave me the earrings. - What? Gold! - the value of gold as a precious metal allows you to interpret the meaning of the word Golden in this context as a positive evaluation. Most often, the evaluation of words of this type manifests itself in the language of the opposition, expressed either implicitly or explicitly: shoes factory quality - artisanal-quality glass vase, a crystal vase and a cotton shirt, synthetic shirt, etc.

Qualitative adjectives in direct value characterizing the subject on the grounds of color, shape and other physical parameters, such as warm (hands), heavy (bag) (KP parametric in the literal); the meaning of these words is dominated by descriptive semes "weight", "shape", "size", "color", and the character contained in these words of evaluation depends on the surrounding context (warm tea is good or bad?).

Relative adjectives are used in a metaphorical qualitative meaning, such as an iron (nerves), doll (appearance) (OP with metaphorical qualitative meaning); this group of words is characterized by the predominance value of the evaluation component above the value of the primitive noun.

Qualitative adjectives in a metaphorical value, characterizing the subject on the grounds of color, shape and other physical parameters, such as a large (heart), warm (atmosphere), cold (reason) (KP parametric in a metaphorical meaning); the meaning of these words dominated by evaluative component when saved as a peripheral SEM "weight", "shape", "size", "color".

Private evaluation qualitative adjectives such as smart, beautiful, essential (KP private evaluation); their value includes the assessment of one aspect of the object.

Total estimated qualitative adjectives such as good, bad, values that contain only this evaluation (estimated total CP).

Grading evaluation capacity is rather arbitrary: it is difficult to define exactly what the word "overestimated" - qualificational relative adjective or adjective of quality, denoting the quality of an object according to certain physical qualificational. However, their differentiation, in our opinion, it is necessary to take a dual function of 
adjectives: denotative and qualificational. In this case, the meaning of a word can be represented as a semantic unit, consisting of a conceptual core and periphery.

\section{Conclusion}

Along with substantive and verbs adjective also forms a kind of node. This node is called the adjectival host. An adverb can manage their dependent words and write the adverbial node. On a hierarchy of nodes adjectival node has fewer items subject to an adjective. This is because in comparison with the verb and substantive (nouns) the adjective has less of the method, compatibility with other words. In languages dependent components in adverbial combinations in relation to the adverb can be used in a preposition - left distribution, and postpositive - right distribution. In IndoEuropean languages, the adjective adjectival nodes can be replaced by participles.

\section{Bibliographic references}

ABDALLAH, S. - GOLD, N. - MARSDEN, A. 2016. Analysing Symbolic Music with Probabilistic Grammars. In D. Meredith (Ed.), Computational Music Analysis (pp. 157-189). Cham: Springer International Publishing. ISBN 978-3-319-25931-4.

ARAÚJO, T. - BANISCH, S. 2016. Multidimensional Analysis of Linguistic Networks. In A. Mehler, A. Lücking, S. Banisch, P. Blanchard, \& B. Job (Eds.), Towards a Theoretical Framework for Analyzing Complex Linguistic Networks (pp. 107-131). Berlin, Heidelberg: Springer Berlin Heidelberg. ISBN 978-3-662-47238-5

BECKAGE, N. M. - COLUNGA, E. 2016. Language Networks as Models of Cognition: Understanding Cognition through Language. In A. Mehler, A. Lücking, S. Banisch, P. Blanchard, \& B. Job (Eds.), Towards a Theoretical Framework for Analyzing Complex Linguistic Networks (pp. 3-28). Berlin, Heidelberg: Springer Berlin Heidelberg. ISBN 978-3-662-47238-5

BIÇICI, E. - WAY, A. 2016. Referential translation machines for predicting semantic similarity. In: Language Resources and Evaluation, vol. 50, n. 4, pp. 793-819. e-ISSN: 1574-0218, ISSN: 1574-0205.

BIRIA, R. - BAHADORAN-BAGHBADERANI, A. 2016. Cross-Cultural Analysis of Prototypicality Norms Used by Male and Female Persian and American Speakers. In: Journal of Psycholinguistic Research, vol. 45, n. 6, pp. 1301-1314. ISSN: 00906905, e-ISSN: 1573-6555.

BJÖRKLUND, J. - FERNAU, H. 2016. Learning Tree Languages. In J. Heinz \& J. M. Sempere (Eds.), Topics in Grammatical Inference (pp. 173-213). Berlin, Heidelberg: Springer Berlin Heidelberg. ISBN 978-3-662-48395-4

CROSSLEY, S. A. - KYLE, K. - MCNAMARA, D. S. 2016. The tool for the automatic analysis of text cohesion (TAACO): Automatic assessment of local, global, and text cohesion. In: Behavior Research Methods, vol. 48, n. 4, pp. 1227-1237. eISSN: $1554-3528$.

D'ASARO, F. A. - DI GANGI, M. A. - PERTICONE, V. - TABACCHI, M. E. 2016. Computational Intelligence and Citizen Communication in the Smart City. In: Informatik-Spektrum, 1-10. ISSN: 0170-6012, e-ISSN: 1432-1221.

FERREIRA, M. 2016. The semantic ingredients of imperfectivity in progressives, habituals, and counterfactuals. In: Natural Language Semantics, vol. 24, n. 4, pp. $353-$ 397. ISSN: 0925-8542, e-ISSN: 1572-8651.

FRANCEZ, N. 2016. A Proof-Theoretic Semantics for Adjectival Modification. In: Journal of Logic, Language and Information, vol. 1, pp. 1-23. ISSN: 0925-8531, eISSN: 1572-9583.

GASIMOV, Z. 2015. Becoming Azerbaijani through Language: On the Impact of Cəlil Məmmədquluzadə’s Anamin Kitabi. In E. Özdalga \& D. Kuzmanovic (Eds.), 
Novel and Nation in the Muslim World: Literary Contributions and National Identities (pp. 48-64). London: Palgrave Macmillan UK.

GASPARYAN, D. 2016. Artificial Intelligence and Semantics through the Prism of Structural, Post-Structural and Transcendental Approaches. In: Integrative Psychological and Behavioral Science, vol. 50, n. 4, pp. 704-743. ISSN: 1932-4502, e-ISSN: 1936-3567.

GIORDANI, A. 2016. An Internal Limit of the Structural Analysis of Causation. In: Axiomathes, vol. 26, n. 4, pp. 429-450. ISSN: 1122-1151, e-ISSN: 1572-8390.

Giuffrè, M. 2017. The Procedural Approach to Texts Text Linguistics and Classical Studies: Dressler and De Beaugrande's Procedural Approach (pp. 35-74). Cham: Springer International Publishing.

GRAMA, I. C. - KERKHOFF, A. - WIJNEN, F. 2016. Gleaning Structure from Sound: The Role of Prosodic Contrast in Learning Non-adjacent Dependencies. In: Journal of Psycholinguistic Research, vol. 45, n. 6, pp. 1427-1449. ISSN: 0090-6905, e-ISSN: 1573-6555.

IOSAD, P. 2016. Prosodic structure and suprasegmental features. The Journal of Comparative Germanic Linguistics, vol. 196 n. 3, pp. 221-268. doi:10.1007/s10828016-9083-8

KEINE, S. - BHATT, R. 2016. Interpreting verb clusters. Natural Language \& Linguistic Theory, vol. 34, n. 4, pp. 1445-1492. ISSN: 0167-8063, e-ISSN: 15730859.

KHAN, G. F. - LEE, S. - PARK, J. Y. - PARK, H. W. 2016. Theories in communication science: a structural analysis using webometrics and social network approach. Scientometrics, vol. 108, n. 2, pp. 531-557. doi:10.1007/s11192-015-18220

LENK, H. 2016. Methodological Perspectivism and Scheme-Interpretationism in Science and Elsewhere. In: Axiomathes, vol. 26, n. 4, pp. 383-399. ISSN: 1122-1151, e-ISSN: $1572-8390$.

LO, S.C. - SUDJATMIKA, F. V. 2016. Solving multi-criteria supplier segmentation based on the modified FAHP for supply chain management: a case study. Soft Computing, vol. 20, n. 12, pp. 4981-4990. ISSN: 1432-7643, e-ISSN: 1433-7479.

MARTINS, M. D. - MARTINS, I. P. - FITCH, W. T. 2016. A novel approach to investigate recursion and iteration in visual hierarchical processing. Behavior Research Methods, vol. 48, n. 4, pp. 1421-1442. ISSN: 0090-5046.

MARUYAMA, Y. 2016. Prior's tonk, notions of logic, and levels of inconsistency: vindicating the pluralistic unity of science in the light of categorical logical positivism. Synthese, vol.193, n. 11, pp. 3483-3495. ISSN: 0039-7857, e-ISSN: 15730964.

NEFDT, R. M. 2016. Scientific modelling in generative grammar and the dynamic turn in syntax. Linguistics and Philosophy, vol. 39, n. 5, pp. 357-394. doi:10.1007/s10988-016-9193-4

ONISHI, T. 2016. Understanding Negation Implicationally in the Relevant Logic R. Studia Logica, vol. 104, n. 6, pp. 1267-1285. ISSN: 0039-3215, e-ISSN: 1572-8730.

RUEGER, A. 2016. Perspectival Realism and Incompatible Models. Axiomathes, vol. 26, n. 4, pp. 401-410. ISSN: 1122-1151, e-ISSN: 1572-8390.

TUNA, T. - AKBAS, E. - AKSOY, A. - CANBAZ, M. A. - KARABIYIK, U. GONEN, B. - AYGUN, R. 2016. User characterization for online social networks. Social Network Analysis and Mining, vol. 6, n. 1, pp. 104. ISSN: 1869-5450, e-ISSN: 1869-5469.

VENTURELLI, E. - CABRINI, E. - FRUGGERI, L. - CIGALA, A. 2016. The study of Triadic Family Interactions: the Proposal of an Observational Procedure. 
Integrative Psychological and Behavioral Science, vol. 50, n. 4, pp. 655-683. ISSN: 1932-4502, e-ISSN: 1936-3567.

WEIDEMAN, A. 2017. A Linguistic Explanation for the Foundations of Applied Linguistics Responsible Design in Applied Linguistics: Theory and Practice (pp. 1138). Cham: Springer International Publishing. ISBN 978-3-319-41731-8.

XIA, F. - LEWIS, W. D. - GOODMAN, M. W. - SLAYDEN, G. - GEORGI, R. CROWGEY, J. - BENDER, E. M. 2016. Enriching a massively multilingual database of interlinear glossed text. Language Resources and Evaluation, vol. 50, n. 2, pp. 321 349. doi:10.1007/s10579-015-9325-4

YALÇIN-HECKMANN, L. - AIVAZISHVILI, N. 2012. Scales of trade, informal economy and citizenship at Georgian-Azerbaijani borderlands. Subverting Borders: Doing Research on Smuggling and Small-Scale Trade (pp. 193-211). Wiesbaden: VS Verlag für Sozialwissenschaften. ISBN: 978-3-531-17788-5.

YANG, M. - LI, P. - ZHU, Q. 2016. Sentence Similarity on Structural Representations. In C.-Y. Lin, N. Xue, D. Zhao, X. Huang, \& Y. Feng (Eds.), Natural Language Understanding and Intelligent Applications: 5th CCF Conference on Natural Language Processing and Chinese Computing, NLPCC 2016, and 24th International Conference on Computer Processing of Oriental Languages, ICCPOL 2016, Kunming, China, December 2-6, 2016, Proceedings (pp. 481-488). Cham: Springer International Publishing.

Words: 7845

Characters: 52065 (28.93 standard pages)

Narmin Abulfaz Aliyeva

The National Academy of Sciences of Azerbaijan

AZ 5000, 24 Istiglaliyyat Street, Baku,

Azerbaijan

rajabova.narmin@gmail.com 